\title{
ЛИТОЛОГИЧЕСКИЕ ОСОБЕННОСТИ ДВУХ СТРУКТУРНО-ФАЦИАЛЬНЫХ ЗОН ОРДОВИКА ПРИБАЛТИКИ
}

Общая структурно-фациальная зональность ордовикских отложений Балтийского бассейна установлена Р. Мяннилем (1966). Ниже рассматриваются основные различия (по минералогическому составу, структурным и текстурным признакам, а также по некоторым общегеологическим данным) между северной и осевой структурно-фациальными зонами в объеме послетремадокского ордовика Северной и Средней Прибалтики (Эстонская и Латвийская ССР) (рис. 1). Сделана также попытка оценить значение этих признаков как фациальных индикаторов. Материалом для данной сводки послужили изученные автором керны многочисленных (более 100) буровых скважин, а также уже опубликованные результаты микролитологического изучения кернов скважин Энгуре и Рапла (Пылма, 1972 а, б), где основное внимание было обращено на всестороннее изучение детрита как одного из основных компонентов рассматриваемых карбонатных отложений.

При характеристике фациальных зон нами было изучено около 25 признаков обломков органических остатков, характеризующих их содержание, морфологию, вторичные изменения и групповой состав. Особо нужно подчеркнуть, что детальное исследование детрита оказывается результативным только при изучении наряду со шлифами также пришлифовок соответствующих представительных образцов.

Общая мощность изученной ордовикской толщи в северной зоне не превышает 200 м, а в осевой, вероятно, не более $230 \mu$. По некоторым отделам и горизонтам наблюдаются существенные колебания мощностей. Так, например, мощность нижнего ордовика без тремадока в осевой зоне в 5-10 раз превышает мощность соответствующих отложений в северной зоне. Относительно выдержанные мощности характерны для среднего ордовика (см. также Jаanusson, 1973).

Зоны значительно различаются по количеству терригенного м а тери ал в карбонатных и терригенно-карбонатных породах (рис. 2). Согласно принятой нами классификации (Вингисаар и др., 1965), в северной зоне преобладают чистые и глинистые известняки, а в осевой - глинистые известняки и мергели (известковые и глинистые). В северной зоне породы с содержанием терригенного материала более $50 \%$ крайне редки.

Раннедиагенетический дол о м т связывается в обеих зонах с низами и верхами ордовика (Пылма, 1972 а, б). Эпигенетическая доломитизация проявляется значительно интенсивнее в северной зоне. В осевой зоне ее 


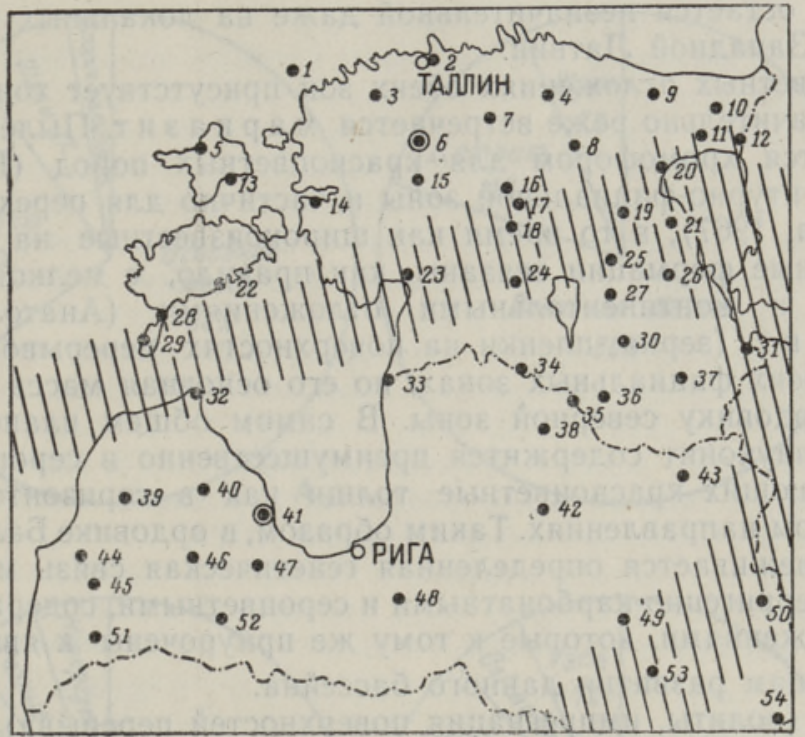

Рис. 1. Схема расположения основных учтенных буровых скважин.

Скважины: 1 - Осмуссааре, 2 - Ласнамяэ, 3 - Вазалемма, 4 - Тапа, 5- Кыргессааре, 6- Рапла (детальную литологическую характеристику см. Пылма, 1972 б), 7 - Арду, 8 - Қамарику, 9 - Савала, 10 - Қайдма, 11 - Ийзаку, $12-$ Яама, 13 - Орьяку, 14 - Хаапсалу, 15 - Лихувески, 16 Эйамаа, 17 - Кабала, 18 - Выхма, 19 - Паламузе, 20 Ранна-Пунгерья, 21 - Ныва, 22 - Кингисеппа, 23 - Пярну, 24 - Вильянди, 25 - Лаэва, 26 - Каагвере, 27 - Кариярве, 28 - Каугатума, 29 - Oхесааре, 30 - Отепя, 31 - Вярска, 28 - Каугатума, 29 - Охесааре, 30 - Отепя, 31 - Волка, 33 - Икла, 34 - Хольдре, 35 - Валга, 36 - Карула, 37 - Выру, 38 - Стренчи, 39- Пилтене, 40 - Талси, 41 - Энгуре (детальную литологическую характеристику см. Пылма, 1972 а), 42 - Дзербене, 43 - Алуксне, 44 - Адзе, 45 Айзпуте, 46 - Қандава, 47 - Виесате, 48 - Балдоне, 49 Аташиене, 50 - Лудза, 51 - Приекуле, 52 - Стури, 53 - Вишки, 54 - Морозики.

Штриховкой показана переходная полоса между северной и осевой структурно-фациальными зонами.

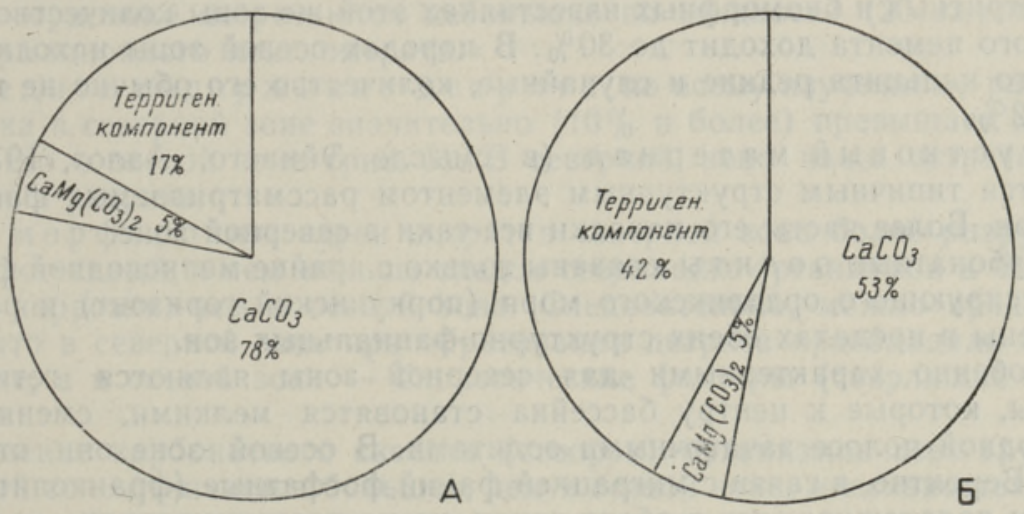

Рис. 2. Средний вещественный состав пород по данным химических анализов.

A - в северной структурно-фациальной зоне (скв, Савала, Рапла, Охесааре -205 анализов); Б- в осевой структурно-фациальной зоне (скв. Энгуре, Адзе, Стури, Приекуле - 275 анализов). 
роль часто остается незначительной даже на локальных тектонических поднятиях Западной Латвии.

В сероцветных отложениях обеих зон присутствует тонкорассеянный п и р и т, значительно реже встречается м а каз и т. Пылеватый ге м а ти т является хромофором для красноцветных пород $\left(\mathrm{B}_{\mathrm{I}}-\mathrm{C}_{\mathrm{I}} \mathrm{c}\right.$ и $\left.\mathrm{F}_{\mathrm{I}} \mathrm{c}\right)$ осевой структурно-фашиальной зоны и частично для переходной полосы (см. Пылма, 1967), в то время как широкоизвестные на земном шаре красноцветные формации связаны, как правило, с мелководными прибрежными и континентальными отложениями (Анатольева, 1972). Г л а укони т (зерна, пленки на поверхностях перерывов) прослеживается в обеих фациальных зонах, но его основная масса приурочена $\mathrm{k}$ нижнему ордовику северной зоны. В самом общем плане можно сказать, что глауконит содержится преимущественно в сероцветных породах, вмещающих красноцветные толщи как в горизонтальном, так и вертикальном направлениях. Таким образом, в ордовике Балтийского бассейна прослеживается определенная генетическая связь между красноцветными терригенно-карбонатными и сероцветными, содержащими глауконит отложениями, которые к тому же приурочены к явно трансгрессивным этапам развития данного бассейна.

Гет и т (оолиты, импрегнация поверхностей перерыва) более характерен для северной зоны, а отчасти также для переходной полосы.

Фосфаты (оолиты, импрегнация поверхностей перерыва) связаны в основном с северной зоной (нижний и средний ордовик). В осевой зоне редкие скопления фосфатов названных выше типов встречены в среднем и верхнем ордовике.

Кероген характерен для северной зоны, исчезая практически полностью в переходной полосе. Что касается нефтяных битумов в карбонатных породах, то их скопления в рассматриваемом регионе явно вторичны и связаны с определенными тектоническими условиями (локальными поднятиями).

Структура карбонатной основной массы известняков в северной зоне главным образом микрокристаллическая, а в осевой зоне преобладает скрытокристаллическая разновидность. Причины здесь, вероятно, фациального, а также постседиментационного характера.

В отложениях северной зоны в торичный (заполняющий поры) к а льц и т присутствует практически повсеместно в количестве $3-5 \%$. А в детритных и биоморфных известняках этой же зоны количество кальцитового цемента доходит до $30 \%$. В породах осевой зоны находки вторичного кальцита редкие и случайные, количество его обычно не превышает $2 \%$.

Сгустковый материал (в смысле Эйнасто, Аалоэ, 1970) не является типичным структурным элементом рассматриваемых фациальных зон. Более часты его находки все-таки в северной зоне.

Карбонатные о олиты связаны только с крайне мелководной фацией регрессирующего ордовикского моря (поркуниский горизонт) и распространены в пределах обеих структурно-фациальных зон.

Особенно характерными для северной зоны являются гетитовые оолиты, которые к центру бассейна становятся мелкими, сменяясь в переходной полосе зачаточными оолитами. В осевой зоне они отсутствуют. Вероятно, в связи с миграцией фаций фосфатные (франколитовые) оолиты прослеживаются в обеих зонах, но на разных уровнях.

Обломочный карбонатный м а тери ал, преимущественно в виде псефита (с размером частиц более 1 мм), встречен главным образом в нижнем и в верхах верхнего ордовика обеих фациальных зон. Однако размеры и частота зерен больше в северной зоне. Здесь во всех 

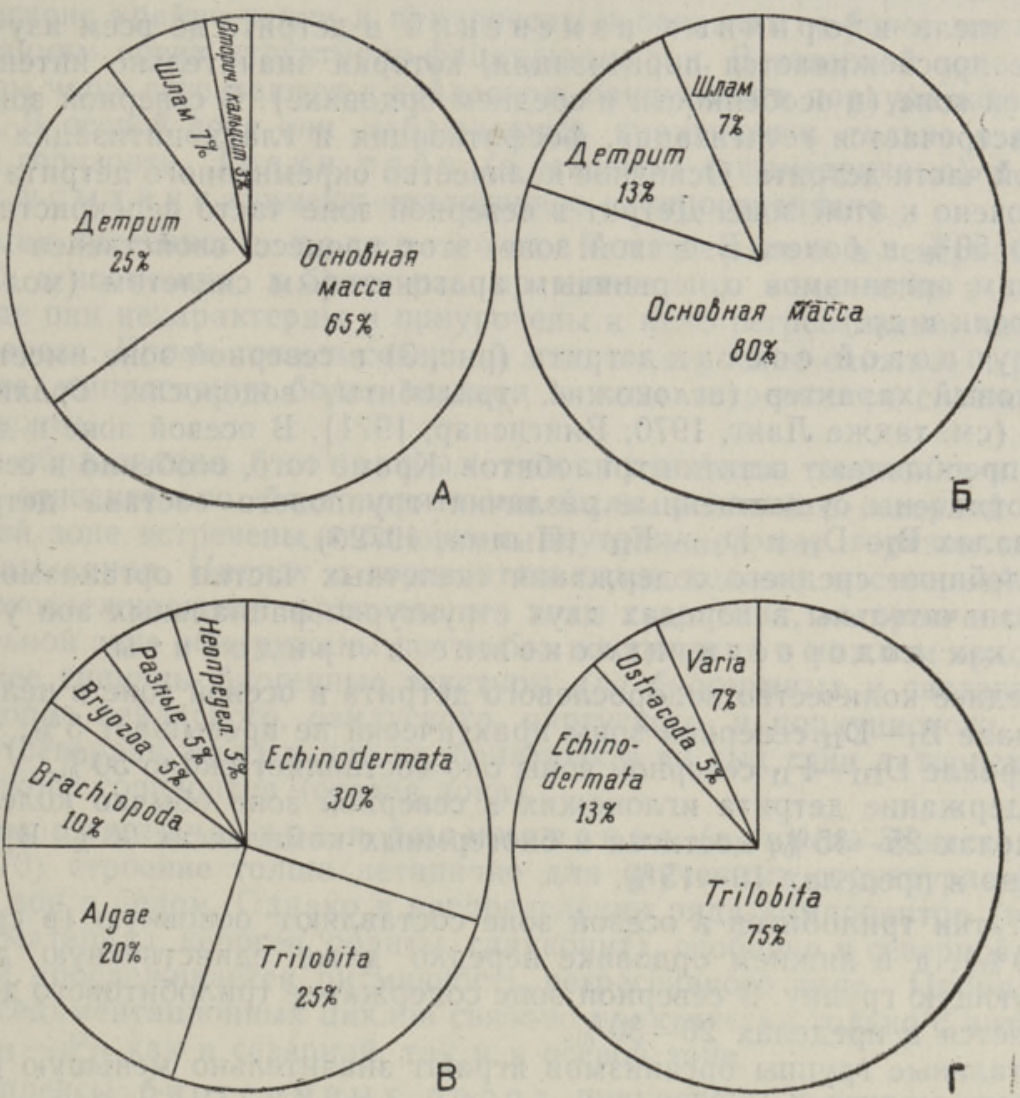

Рис. 3. Приближенный средний состав основных структурных компонентов $(A, E)$ и приближенный средний групповой состав детрита $(B, \Gamma)$ по данным шлифов:

$A, B$ - в северной структурно-фациальной зоне (по данным около 400 шл.); Б, $\Gamma$ - в осевой структурно-фациальной зоне (около 300 шл.).

отделах ордовика встречаются небольшие по мощности (20 cм) линзы межформационного конгломерата.

С реднее соде ржание де т р и та по всему изученному разрезу ордовика в северной зоне значительно (10\% и более) превышает содержание его в осевой зоне (рис. 3). В северной зоне чаще встречаются скопления детрита.

По морфологи и зерен детрит в северной зоне более разрушенный и окатанный, в нем меньше следов сверлящих организмов и больше следов коррозии, чем в осевой зоне. Следовательно, можно предположить, что в северной зоне при образовании детрита преобладали механические, а в осевой зоне - биологические факторы (сверлящие организмы).

Строение карбонатного скелета (створок) организмов всех групп в северной зоне отличается большей, чем в осевой зоне, массивностью.

Пространственное распределени е детрита в породах северной зоны в подавляющем большинстве случаев неравномерное, в осевой зоне оно более равномерное. О ри ента ци я детрита в породах обеих зон в основном беспорядочная. Горизонтальная упаковка детрита встречается как исключение. 
Из числа в торичных изменени й в детрите во всем изученном районе прослеживается пиритизация, которая значительно интенсивнее в осевой зоне (в особенности в среднем ордовике). В северной зоне местами встречается гетитизация, фосфатизация и глауконитизация значительной части детрита. Основное количество окремненного детрита также приурочено к этой зоне. Детрит в северной зоне часто перекристаллизован до $50 \%$ и более. В осевой зоне этот процесс свойственен только остаткам организмов с первичным арагонитовым скелетом (моллюски, водоросли и др.).

Г ру п п во й состав детрита (рис. 3) в северной зоне имеет полидетритовый характер (иглокожие, трилобиты, водоросли, брахиоподы и др.) (см. также Ланг, 1970; Вингисаар, 1971). В осевой зоне в детрите резко преобладают остатки трилобитов. Кроме того, особенно в северной зоне, отмечены существенные различия группового состава детрита в интервалах $\mathrm{B}_{\mathrm{I}}-\mathrm{D}_{\mathrm{II}}$ и $\mathrm{D}_{\mathrm{JU}}-\mathrm{F}_{\mathrm{II}}$ (Пылма, 1972б).

Колебания среднего содержания скелетных частиц организмов наиболее значительны в породах двух структурно-фациальных зон у таких групп, как водоросли, иглокожие и трилоби ты.

Среднее количество водорослевого детрита в осевой зоне в целом и в интервале $\mathrm{B}_{\mathrm{I}}-\mathrm{D}_{\mathrm{II}}$ северной зоны практически не превышает $5 \%$; только в интервале $\mathrm{D}_{\mathrm{III}}-\mathrm{F}_{\mathrm{II}}$ северной зоны оно составляет около $50 \%$.

Содержание детрита иглокожих в северной зоне обычно колеблется в пределах $25-35 \%$, достигая в биогермных комплексах $90 \%$. В осевой зоне оно в пределах $10-15 \%$.

Остатки трилобитов в осевой зоне составляют основную (в среднем $70-80 \%$ ), а в нижнем ордовике нередко даже единственную детритобразующую группу. В северной зоне содержание трилобитового детрита колеблется в пределах $20-30 \%$.

Остальные группы организмов играют значительно меньшую роль в образовании детрита.

Обломков брахиопод в детрите северной зоны в среднем около $10 \%$, а в осевой $3-6 \%$.

Количество остра кодового детрита в северной зоне редко превышает $3 \%$, а в осевой зоне его содержание колеблется в пределах $5-7 \%$.

Среднее содержание детрита мшанок в северной зоне в отдельных случаях достигает $30 \%$, но в основном остается в пределах $10 \%$. В осевой зоне первые фрагменты мшанок появляются только начиная с ласнамягиского горизонта и среднее количество их не превышает $5 \%$.

Детрит моллюсков присутствует в северной зоне в количестве $4-6 \%$, а в осевой зоне местами встречены лишь единичные обломки.

В группу varia (р а з ны е) в обеих фациальных зонах вошли спорадические находки детрита таких групп фауны, как ругозы, табуляты, строматопороидеи, губки и граптолиты. Обломки первых трех групп в осевой зоне связаны только с поркуниским горизонтом. Остатки губок более характерны для северной, а граптолитовый детрит - для осевой зоны.

По количеству шлам а (скелетные остатки организмов размером менее 0,1 мм) существенных различий между зонами не прослеживается.

В рассматриваемых фациальных зонах из числа слоистых текстур преобладают слабо волнистые тонко- и среднеслоистые разновидности.

Комковатые текстуры в основном свойственны верхнему ордовику северной зоны и переходной полосы. Полукомковатые текстуры чаще встречаются в осевой зоне. 
Микрослойчатость и косая слои стость в рассматриваемом регионе крайне редки и приурочены в основном к более мелководным фациям обеих структурно-фациальных зон. В северной зоне такие текстуры чаще встречаются в кейласком, оандуском и поркуниском горизонтах. В осевой зоне они наблюдаются практически только в поркуниском горизонте. 3 на ки ряби (в основном асимметричные) и т ре щи ны усых ан ия имеют аналогичное распространение.

Общая численность пов ерхностей переры в а в северной зоне в 5-10, а возможно, и более раз превышает их количество в осевой зоне, где они нехарактерны и приурочены к явно регрессивным интервалам разреза. Кроме того, в северной зоне их строение сложнее и разнообразнее, импрегнация более мощная и чаще встречаются сглаженные поверхности.

Для образования би огенных текстур (ходы сверления и зарывания) относительно благоприятными были условия в северной зоне. В осевой зоне встречены в основном внутрипластовые горизонтальные ходы зарывания. Наряду с горизонтальными ходами в северной зоне часто прослеживаются вертикальные ходы сверления, которые в осевой фациальной зоне обнаружены почти без исключения в нижнем ордовике. Наименее типичны биогенные текстуры для биогермных и связанных с ними пород кейлаского, оандуского, пиргуского и поркуниского горизонтов (северная зона) и для карбонатных и чистых глин латорпского и волховского горизонтов (осевая зона).

Ясное циклическое и ритмическое (в смысле Эйнасто, Нестор, 1970) строение толщи нетипнчно для изученных структурно-фациальных зон в целом. Однако в распределении ряда компонентов (терригенный материал, кероген, оолиты, глауконит), особенно в северной зоне, местами прослеживается ритмичность регрессивного типа. Проявление четких седиментационных циклов связано практически только с интервалом $\mathrm{D}_{\mathrm{III}}-\mathrm{F}_{\mathrm{II}}$ как в северной, так и в осевой зоне.

Комплексы биогермных пород приурочены к верхам среднего ордовика и верхнему ордовику северной зоны и имеют здесь явно регрессивный характер распространения (Мянниль, Эйнасто, 1968).

Большинство изложенных выше литологических признаков (глинистость и красноцветность пород; содержание фосфатов, керогена, гетитовых оолитов, карбонатного обломочного материала; характеристика детрита и т. д.) позволяет провести четкое различие между изученными зонами. В основном эти различия сингенетические, т. е. имеют фациальный характер. Что касается таких признаков, как структура основной массы, перекристаллизация детрита и др., то они обусловлены прежде всего существенными различиями в послеордовикском развитии данной территории. В то время как отложения осевой фациальной зоны были погружены на значительные глубины и сохранялись в устойчивых термодинамических условиях, отложения большей части северной зоны были приподняты и находились в длительные геологические периоды в условиях активного водообмена и под влиянием метеорных вод.

Существует также ряд литологических признаков (содержание раннедиагенетического доломита, пирита, глауконита, франколитовых оолитов, шлама; некоторые текстурные особенности и т. д.), по которым различия между зонами незначительны или вовсе отсутствуют. Это, вероятно, указывает на относительную однородность топографии дна обеих зон бассейна, особенно в первой половине рассматриваемого периода ( $\left.\mathrm{B}_{\mathrm{I}}-\mathrm{D}_{\mathrm{II}}\right)$. При этом не исключена возможность, что в отдельные моменты (например $\mathrm{C}_{\text {II }}$ ) этого периода в осевой структурно-фациальной зоне осадконакопление протекало даже в более мелководных условиях, чем в значи- 
тельной части северной структурно-фациальной зоны. В преобладающей части второй половины рассматриваемого периода $\left(\mathrm{D}_{\mathrm{III}}-\mathrm{F}_{\mathrm{I}} \mathrm{c}\right)$ условия седиментации в осевой зоне оставались существенно более глубоководными, чем на севере. В качестве подтверждения тому можно указать хотя бы на распространение в осевую зону прослоев темных граптолитовых илов (свиты моссен и фяка), непосредственно связанных с геосинклинальной областью. Аналогично, как и во втором периоде, четкие различия между фациальными зонами сохранились также в силуре Прибалтики.

Выявленные литологические особенности двух структурно-фациальных зон ордовика Балтийского эпиконтинентального бассейна, имевшего нормальную соленость воды, позволяют рассматривать слагающие их карбонатные породы в качестве отложений преимущественно на умеренных (северная) и средних (осевая зона) глубинах ниже уровня (особенно в осевой зоне) постоянного активного действия волн. Более мелководные прибрежные ордовикские отложения почти полностью уничтожены последующей денудацией.

\section{Л И Т Е Р А Т Р А}

Ан а тольев а А. И. 1972. Домезозойские красноцветные формации. Новосибирск.

В инги с а а П., О р ас пыльд А., Эйнасто Р., Юргенсон Э. 1965. Единая классификация и легенда карбонатных пород. Таллин.

В инги са а р П. 1971. Микролитологическое исследөвание известняков ордовикского разреза скважины Хаапсалу. Изв. АН ЭССР, Хим. Геол., 20, № 1.

Л а н г Т. 1970. Фащии детрита ореднеордовикской сланценосной толщи Севера Прибалтики. Тезисы докл. VII науч. жонфер. геологов Прибалтики и Белоруссии. Таллин.

Мянни и л Р. М. 1966. История развития Балтийского бассейна в ордовике. Таллин.

М янниль Р. М., Эй н а с то Р. Э. 1968. Распространение рифогенных образований ордовика и силура в Балтийском бассейне. В сб.: Ископаемые рифы и методика их изучения. Свердловск.

Пы лм а Л. 1967. О переходной полосе между северной и осевой фациальными зонами ордовика Прибалтики. Изв. АН ЭССР, Хим. Геол., 16, № 3.

П ы л м а Л. 1972 а. Состав и количество детрита в отложениях осевой фациальной зоны ордовика Прибалтики (по скважине Энгуре). Изв. АН ЭССР, Хим. Геол., 21, № 2.

П ыл м а Л. 1972 б. Состав и количество детрита в отложениях северной фациальной зоны ордовика Прибалтики (по скважине Рапла). Изв. АН ЭССР, Хим. Геол., 21, № 4 .

Эй н а с т о Р., А а л оэ А. 1970. Зернистые известняки. В кн.: Силур Эстонии. Таллин.

Э й н асто Р., Н есто Р X. 1970. О фациальной зональности и седиментационной цикличности карбонатных отложений силура Прибалтики. Тезисы докл. VII науч. конфер. геологов Прибалтики и Белоруссии. Таллин.

$\mathrm{J}$ a a nus son V. 1973. Aspects of carbonate sedimentation in the Ordovician of Baltoscandia. Lethaia, 6 , No. 1.

Ннститут геологии

Академии наук Эстонской ССР

Поступила в редакцию 6/III 1973

\section{POLMA}

\section{BALTIKUMI ORDOVIITSIUMIBASSEINI KAHE STRUKTUURILIS- FATSIAALSE VOONDI LITOLOOGILISED ERINEVUSED}

Artiklis esitatakse lühidalt Baltikumi ordoviitsiumibasseini pöhja- ja keskvööndi karbonaatse settekompleksi vōrdlev-litoloogiline iselcomustus peamiselt uuritud struktuuriliste ja tekstuuriliste tunnuste alusel. Seejuures pööratakse tavalisest suuremat tähelepanu detriidi morfoloogia, grupilise koostise, sekundaarsete muutuste ja teiste tunnuste iseloomustamisele. Uurimiste tulemusena selgus, et kahe iseloomustatud struk- 
tuurilis-fatsiaalse naabervööndi vahel on olulised litoloogilised erinevused. Ainult üksikutel suhteliselt lühiajalistel perioodidel või mōnede üldisemat laadi litoloogiliste tunnuste osas on need erinevused minimaalsed.

\section{POLMA}

\section{LITHOLOGICAL DIFFERENCES BETWEEN TWO STRUCTURAL-FACIAL BELTS OF THE EAST BALTIC ORDOVICIAN}

Lithological differences between the northern and axial structural-facial belts of the East Baltic Ordovician carbonate deposits are presented in brief, mostly by means of various textural and structural features. More importance than usual is attributed to the characterisation of skeletal debris (by the point-counting method). Investigations show that lithological differences between the two neighbouring facial zones are mostly essential. Only during some short periods and in respect to a few general lithological characters these differences may be slight. 